\title{
Mutations in the Mitochondrial ND1 Gene Are Associated with Postoperative Prognosis of Localized Renal Cell Carcinoma
}

\author{
Hakushi Kim ${ }^{1, *}$, Tomoyoshi Komiyama ${ }^{2}$, Chie Inomoto ${ }^{3}$, Hiroshi Kamiguchi ${ }^{4}$, \\ Hiroshi Kajiwara ${ }^{3}$, Hiroyuki Kobayashi ${ }^{2}$, Naoya Nakamura ${ }^{3}$ and Toshiro Terachi ${ }^{1}$ \\ 1 Department of Urology, Tokai University School of Medicine, Kanagawa, Isehara 259-1193, Japan; \\ terachit@is.icc.u-tokai.ac.jp \\ 2 Department of Clinical Pharmacology, Tokai University School of Medicine, Kanagawa, \\ Isehara 259-1193, Japan; komiyama@tokai-u.jp (T.K.); hkobayas@is.icc.u-tokai.ac.jp (H.Ko.) \\ 3 Department of Pathology, Tokai University School of Medicine, Kanagawa, Isehara 259-1193, Japan; \\ cisophia.ci@gmail.com (C.I.); h-kaji@is.icc.u-tokai.ac.jp (H.Ka.); naoya@is.icc.u-tokai.ac.jp (N.N.) \\ 4 Support Center for Medical Research and Education, Tokai University, Kanagawa, Isehara 259-1193, Japan; \\ kamiguchi@is.icc.u-tokai.ac.jp \\ * Correspondence: qblong888@gmail.com; Tel.: +81-463-93-1121
}

Academic Editor: William Chi-shing Cho

Received: 26 October 2016; Accepted: 29 November 2016; Published: 7 December 2016

\begin{abstract}
We analyzed mutations in the mitochondrial ND1 gene to determine their association with clinicopathological parameters and postoperative recurrence of renal cell carcinoma (RCC) in Japanese patients. Among 62 RCC cases for which tumor pathology was confirmed by histopathology, ND1 sequencing revealed the presence of 30 mutation sites in 19 cases. Most mutations were heteroplasmic, with 16 of 19 cases harboring one or more heteroplasmic sites. Additionally, 12 sites had amino acid mutations, which were frequent in 10 of the cases. The 5-year recurrence-free survival (RFS) rate was significantly worse in patients with tumors $>40 \mathrm{~mm}$ in diameter $(p=0.0091)$, pathological $\mathrm{T}(\mathrm{pT})$ stage $\geq 3(p=0.0122)$, Fuhrman nuclear atypia grade $\geq$ III $(p=0.0070)$, and ND1 mutations $(p=0.0006)$. Multivariate analysis using these factors revealed that mutations in ND1 were significantly associated with the 5-year RFS rate $(p=0.0044)$. These results suggest a strong correlation between the presence of ND1 mutations in cancer tissue and postoperative recurrence of localized RCC in Japanese patients.
\end{abstract}

Keywords: mitochondrial DNA; ND1; renal cell carcinoma; prognostic factor; polymorphism; heteroplasmy; nucleotide differentiation index

\section{Introduction}

Kidney cancer is globally the 9th and 14th most common malignant tumor among males and females, respectively [1]. In developed countries, renal cell carcinoma (RCC) constitutes $85 \%-90 \%$ of all cancers of the kidney [2,3]. There is a 1.5:1 predominance of new RCC cases in males over females, and the peak age of onset is between 60 and 70 years [4]. The advent and widespread use of abdominal imaging techniques, such as abdominal ultrasonography and computed tomography, has led to the increased frequency of the diagnosis of small asymptomatic RCCs, which account for about half of all newly diagnosed cases [5]. Despite the increase in the number of new cases, the mortality rate due to RCC has, in fact, decreased [6,7]. However, even in patients with localized RCC that has been resected with curative surgery, such as total or partial nephrectomy, the relapse rate is about $20 \%-40 \%$, with progression to metastatic RCC (mRCC) [8]. 
These observations suggest that even small RCCs can exhibit aggressive metastatic ability to distant organs [9]. In addition, given the lack of an effective adjuvant therapy to reduce the risk of recurrence after curative surgery, early detection and intervention in patients with recurrent RCC is critical to improving prognosis in mRCC. However, there are no established prognostic models to accurately predict the metastatic potential of RCCs. Recent studies suggested that several prognostic models that were developed based on the TNM system may not effectively predict the postoperative prognosis of distinct RCC types, and the development of improved models with increased accuracy for recurrence patterns is sorely needed [10-12]. Additionally, diagnostic and prognostic molecular markers for RCC have not yet been fully incorporated into clinical practice [13,14].

Human mitochondrial DNA (mtDNA) is a closed, circular molecule comprising 16,569 nucleotide pairs and encoding 13 essential genes with roles in oxidative phosphorylation as well as the structural rRNA and tRNAs necessary for the expression of these genes [15]. mtDNA is encoded separately from nuclear DNA and is in close proximity to reactive oxygen species (ROS) due to functional necessity. For this reason, and as histone proteins that protect nuclear DNA are missing in mitochondria, mtDNA accumulates mutations at a higher rate than nuclear DNA, which subsequently affect the oxidative phosphorylation capacity of mitochondria [16].

Recent studies proposed that mutations in mtDNA might be utilized as molecular markers for early detection, assessment of the degree of malignancy, and prediction of recurrence and prognosis after radical surgery in several cancer types. $[17,18]$. mtDNA mutations that resulted in ROS accumulation were shown to be correlated with the acquisition of metastatic potential and poor prognosis [19]. For example, Bai et al. demonstrated the association of a nine-base pair deletion at nucleotide position 8272 (region V) of the mtDNA with postoperative survival rate in RCC [20]. In addition, mutations in NADH dehydrogenase subunit 1 (ND1), a subunit of oxidative phosphorylation complex, were detected in breast and nasopharyngeal carcinomas [21,22]. Furthermore, Yusnita et al. [23] identified 11 missense mutations in ND1 from colorectal tumor tissue specimens. Studies also showed that mutations in ND1 may lead to changes in the secondary structure of the protein and subsequent inactivation of enzymes [23]. The studies described above indicate that there was a correlation between various types of cancer and the ND1 mutations, which may lead to subsequent abrogation of its enzymatic activity [21-23]. These studies provide strong evidence for the utility of mtDNA mutations as potential prognostic factors for recurrence and progression in various types of cancer.

In this study, we aimed to determine the correlation between mtDNA mutations and postoperative recurrence in RCC. We performed comparative sequence analysis of mtDNA extracted from formalin-fixed paraffin-embedded (FFPE) RCC and the paired non-cancerous tissue specimens to evaluate postoperative gene markers as prognostic factors.

\section{Results}

\subsection{Clinical Characteristics of Study Subjects}

Characteristics of patients and tumor specimens are summarized in Table 1. Median age was 62 (39-80) years, and male-to-female ratio was 3.4:1. Median follow-up period was 66.5 (29-76) months. From 62 subjects in this study that were followed up with for a minimum of two years, 11 had recurrent RCC by June 2016. Among pathological characteristics, median tumor diameter in the surgical specimen was 32 (12-105) mm. Histologically, 55 patients had clear cell RCC (ccRCC), whereas tumors were non-clear cell RCC (nccRCC) in the remaining seven cases. By histopathological diagnosis, tumors were locally confined (stage pT1-2) in 57 patients, whereas tumors invaded the vascular or surrounding tissue (pathological T (pT) stage 3-4) in five patients. By Fuhrman grading of nuclear atypia, 54 and eight cases were grade I/II and III/IV, respectively. Microvessel invasion was observed in 12 patients. 
Table 1. Patient and tumor characteristics of 62 cases with localized renal cell carcinoma.

\begin{tabular}{cc}
\hline Age (years), Median (range) & $62(39-80)$ \\
Sex (male/female) & $48 / 14$ \\
Nephrectomy (total/partial) & $42 / 20$ \\
Observation (months), median (range) & $66.5(29-76)$ \\
Tumor diameter (mm), median, range & $32(12-105)$ \\
\hline Histology type & 55 \\
clear & 2 \\
papillary & 3 \\
chromophobe & 1 \\
multilocular & 1 \\
acquired cystic disease (ACD)-associated & \\
Pathological T stage & 40 \\
T1a & 14 \\
T1b & 3 \\
T2a & 0 \\
T2b & 1 \\
T3a & 3 \\
T3b & 1 \\
T4 & \\
Fuhrman & 1 \\
G1 & 53 \\
G2 & 6 \\
G3 & 2 \\
G4 & 50 \\
V0 & 12 \\
\hline V1 & \\
\hline
\end{tabular}

\subsection{Nucleotide Differentiation Index Analysis $\left(N_{S T}\right)$}

In this study comprising 62 Japanese patients with RCC, we investigated the ND1 gene using the nucleotide differentiation index $\left(N_{\mathrm{ST}}\right)$ [24]. As controls, ND1 sequences of 62 healthy Japanese subjects were obtained from GenBank. We determined that the $N_{\mathrm{ST}}$ was 0.005 , indicating that RCC was significantly associated with mutations in the mitochondrial ND1 gene.

\subsection{Analysis of ND1 Mutations}

We analyzed the ND1 sequences (956 base pairs) using the FFPE tissue specimens of 62 patients with RCC. We found somatic mutations, including heteroplasmy, at 30 sites in 19 cases $(30.6 \%$; 19/62 patients) (Figure 1). Only one site (3970) was confirmed to have both homoplasmic and heteroplasmic mutations. In addition, C3328Y, C4197Y, and C4141Y with heteroplasmic mutations were novel mutations that were not previously reported in Japanese patients. Moreover, mutations leading to amino acid changes were observed at 12 sites in 10 cases $(52.6 \%, 10 / 19$ patients). The ND1 region of patient hk383 harbored a mutation, insertion of a $C$ at position 3572 , which caused a frameshift. Heteroplasmic mutations were observed at 24 sites in 16 cases $(84.2 \%, 16 / 19$ patients), and $84 \%$ of the cases with mutations harbored heteroplasmic mutations (Table 2). Since mtDNA is generally homoplasmic, heteroplasmic mutations observed in this cohort were considered to have occurred as part of changes in conditions related to RCC. 


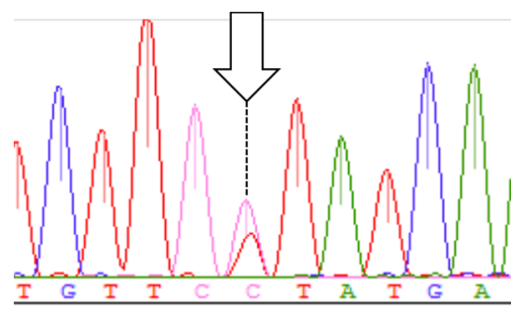

Figure 1. The signal of the heteroplasmic mutation site.

Table 2. Nucleotide (single nucleotide mutation or heteroplasmic change) and amino acid changes in the ND1 gene.

\begin{tabular}{|c|c|c|c|c|c|}
\hline Patient & Base Change & AA Change & Heteroplasmy & Histology Type & Outcome \\
\hline hk347 & $\begin{array}{l}\text { C4197Y * } \\
\text { T4248Y }\end{array}$ & & $\begin{array}{l}+ \\
+\end{array}$ & Clear cell & No recurrence \\
\hline hk355 & C3497T & $\mathrm{A} 64 \mathrm{~V}$ & & Clear cell & No recurrence \\
\hline hk357 & C4197Y* & & + & Clear cell & No recurrence \\
\hline hk362 & C3970Y & & + & Clear cell & No recurrence \\
\hline hk363 & T4248Y & & + & Clear cell & No recurrence \\
\hline hk364 & $\begin{array}{l}\text { C3497T } \\
\text { G3635A }\end{array}$ & $\begin{array}{l}\text { A64V } \\
\text { S110N }\end{array}$ & & Clear cell & No recurrence \\
\hline hk368 & $\begin{array}{l}\text { C4197Y* } \\
\text { T4248Y }\end{array}$ & & $\begin{array}{l}+ \\
+ \\
\end{array}$ & Clear cell & No recurrence \\
\hline hk372 & $\begin{array}{c}\text { A4200W } \\
\text { T4216Y }\end{array}$ & $\mathrm{Y} 304 \mathrm{H}$ & $\begin{array}{l}+ \\
+\end{array}$ & Clear cell & Recurrence \\
\hline hk382 & $\begin{array}{c}\text { A4200W } \\
\text { T4216Y }\end{array}$ & $\mathrm{Y} 304 \mathrm{H}$ & $\begin{array}{l}+ \\
+\end{array}$ & Clear cell & No recurrence \\
\hline hk383 & C3572ins & L89P (Frameshift) & & Clear cell & Recurrence \\
\hline hk385 & $\begin{array}{c}\text { G3496T } \\
\text { C4141Y* } \\
\text { T4248Y }\end{array}$ & $\begin{array}{c}\text { A64S } \\
\text { R279W }\end{array}$ & $\begin{array}{l}+ \\
+ \\
\end{array}$ & Clear cell & $\begin{array}{l}\text { Recurrence/Cancer } \\
\text { Death }\end{array}$ \\
\hline hk387 & $\begin{array}{l}\text { C4197Y* } \\
\text { T4248Y }\end{array}$ & & $\begin{array}{l}+ \\
+ \\
\end{array}$ & Clear cell & Recurrence \\
\hline hk392 & $\begin{array}{l}\text { G4048R } \\
\text { C4071Y }\end{array}$ & $\mathrm{D} 248 \mathrm{~N}$ & $\begin{array}{l}+ \\
+ \\
\end{array}$ & $\begin{array}{c}\text { ACD-associated } \\
\text { RCC }\end{array}$ & Recurrence \\
\hline hk393 & T3368Y & M21T & + & Clear cell & No recurrence \\
\hline hk394 & $\begin{array}{c}\text { A4200W } \\
\text { T4216Y }\end{array}$ & $\mathrm{Y} 304 \mathrm{H}$ & $\begin{array}{l}+ \\
+\end{array}$ & Clear cell & Recurrence \\
\hline hk399 & C3970Y & & + & Clear cell & Recurrence \\
\hline hk401 & $\mathrm{T} 4117 \mathrm{Y}$ & & + & Clear cell & $\begin{array}{c}\text { No recurrence } \\
\text { (Figure 1) }\end{array}$ \\
\hline hk403 & $\begin{array}{l}\text { C3328Y* } \\
\text { C3970T }\end{array}$ & $\mathrm{L} 8 \mathrm{~F}$ & + & Clear cell & $\begin{array}{c}\text { Recurrence/Cancer } \\
\text { Death }\end{array}$ \\
\hline hk405 & G4113R & & + & Clear cell & No recurrence \\
\hline
\end{tabular}

\subsection{Analysis of Recurrence Risk Factors and Cancer-Specific and Overall Survival}

The 5-year recurrence-free survival (RFS), cancer specific survival (CSS), and overall survival (OS) were $81.6 \%, 96.7 \%$, and $93.4 \%$ by the Kaplan-Meier analysis, respectively (Figure 2). Among the ten factors that were assessed by the log-rank test, four factors (maximum tumor diameter, $\mathrm{pT}$ stage, Fuhrman grade, and ND1 mutation) were significantly associated with recurrence, suggesting that 
these factors might impact RFS: tumor diameter (5-year RFS, $89.9 \%$ and $64.3 \%$ for $\leq 40$ and $>40 \mathrm{~mm}$, respectively; $p=0.0091$ ), $\mathrm{pT}$ stage (5-year RFS, $85.6 \%$ and $40.0 \%$ for $\leq \mathrm{pT} 2$ and $\geq \mathrm{pT} 3$, respectively; $p=0.012$ ), Fuhrman grade (5-year RFS, $86.6 \%$ and $50.0 \%$ for I/II and III/IV, respectively; $p=0.0070$ ), and somatic mutation in ND1 (5-year RFS, $59.1 \%$ and $94.6 \%$ for the presence and absence of somatic mutation/s in ND1, respectively; $p=0.0006$ ) (Table 3) (Figure 3). Multivariate analysis using the Cox proportional hazards model using these four factors showed that only the presence of somatic mutations in the ND1 gene was a significant factor associated with RFS ( $p=0.0044)$ (Table 4). We also examined the association of these ten factors with CSS using the log-rank test. As a result, three factors (maximum tumor diameter, pT stage, and ND1 mutation) were found to be significantly associated with CSS: tumor diameter (5-year CSS, $100 \%$ and $90 \%$ for $\leq 40 \mathrm{~mm}$ and $>40 \mathrm{~mm}$, respectively; $p=0.0415$ ), pT stage (5-year CSS, $98.2 \%$ and $80.0 \%$ for $\leq \mathrm{pT} 2$ and $\geq \mathrm{pT} 3$, respectively; $p=0.0330$ ), and somatic mutation in ND1 (5-year CSS, $89.5 \%$ and $100 \%$ for the presence and absence of somatic mutation/s in ND1, respectively; $p=0.0341$ ) (Table 5). Multivariate analysis using the Cox proportional hazards model for these three factors showed that there was no factor significantly associated with CSS; however, somatic mutation in ND1 showed a tendency toward deterioration of CSS in the presence of ND1 mutation ( $p=0.0827$ ) (Table 6). These findings suggest that mutations in ND1 might also be considered as a prognostic factor for recurrence and a possible predictor of CSS. Among the cCRCC subgroup (55 cases), we examined the association of RFS with the same nine factors using the log-rank test and Cox proportional hazards model. As a result of the log-rank test, three factors (maximum tumor diameter $(p=0.0161)$, Fuhrman grade $(p=0.0051)$, and ND1 mutation $(p=0.0042))$ were candidates of becoming independent predictors of RFS. Finally, ND1 mutation was the only statistically significant predictive factor of RFS in the ccRCC sub group according to the Cox proportional hazards model $(p=0.0208)$ (Table 7).

(a)

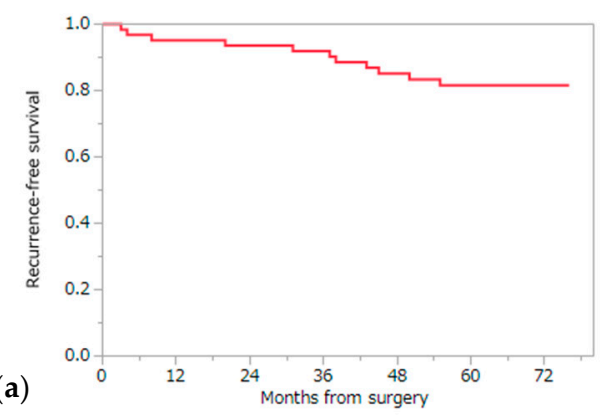

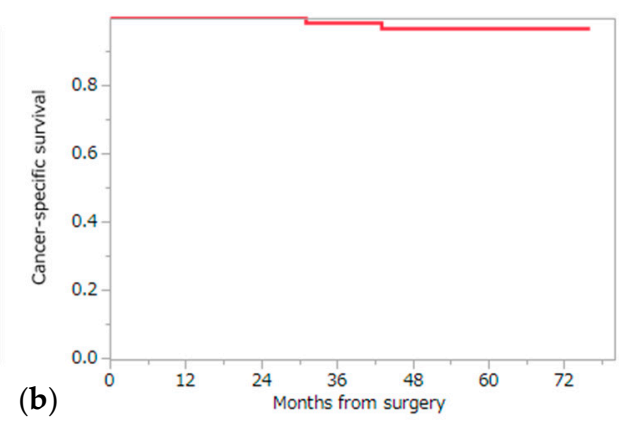

(b)

Figure 2. Kaplan-Meier curve for the 5-year RFS (a) and CSS (b) of a total of 62 patients included in this study.

Table 3. Univariate analysis of factors predicting recurrence after surgery.

\begin{tabular}{cccc}
\hline Variables & No. of Cases & 5-Year RFS Rate (\%) & $p$ Value \\
\hline Age (years) & & & 0.1736 \\
$\leq 60$ & 28 & 88.7 & \\
$>60$ & 34 & 75.7 & 0.2690 \\
Sex & 14 & 91.7 & \\
Female & 48 & 78.7 & 0.7795 \\
Male & & & \\
Tumor localization & 24 & 83.1 & 0.2951 \\
Left & 38 & 80.4 & \\
Right & & & \\
\hline Nephrectomy & 42 & 78.1 & \\
Total & 20 & 89.2 & \\
Partial & &
\end{tabular}


Table 3. Cont.

\begin{tabular}{|c|c|c|c|}
\hline Variables & No. of Cases & 5-Year RFS Rate (\%) & $p$ Value \\
\hline Tumor diameter (mm) & & & $0.0091^{* *}$ \\
\hline$\leq 40$ & 42 & 89.9 & \\
\hline$>40$ & 20 & 64.3 & \\
\hline Histological type & & & 0.9142 \\
\hline clear & 56 & 81.6 & \\
\hline non-clear & 6 & 80.0 & \\
\hline pT stage & & & $0.0122 * *$ \\
\hline$\leq \mathrm{pT} 2$ & 57 & 85.6 & \\
\hline$\geq \mathrm{pT} 3$ & 5 & 40.0 & \\
\hline Fuhrman grade & & & $0.0070 * *$ \\
\hline $\mathrm{I} / \mathrm{II}$ & 54 & 86.6 & \\
\hline III/IV & 8 & 50.0 & \\
\hline Vessel invasion & & & 0.1389 \\
\hline Presence & 50 & 66.7 & \\
\hline Absence & 12 & 85.5 & \\
\hline ND1 somatic mutation & & & $0.0006^{* *}$ \\
\hline Presence & 19 & 57.9 & \\
\hline Absence & 43 & 92.4 & \\
\hline
\end{tabular}

** Statistical significance was set to $p<0.05$.
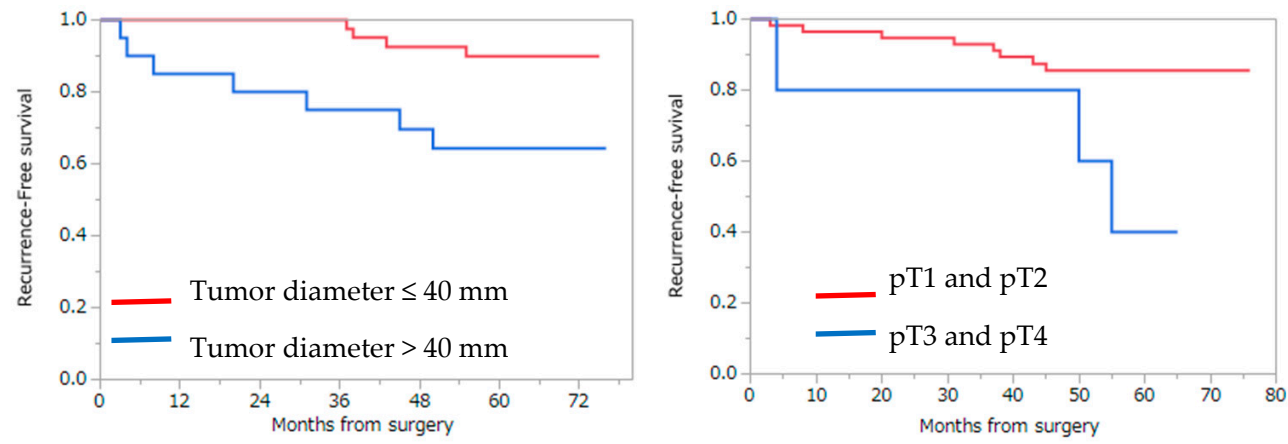

a. Tumor diameter.

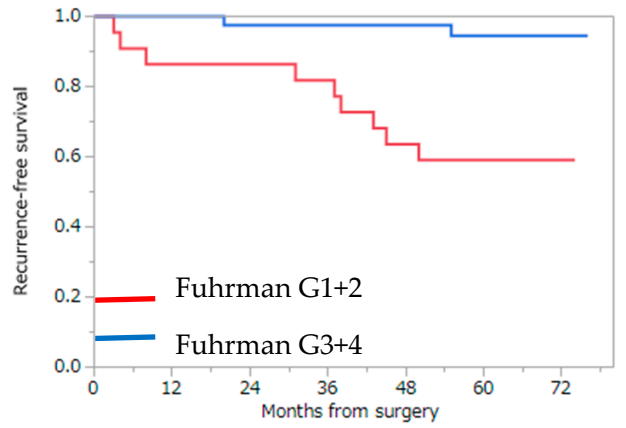

b. pT stage.

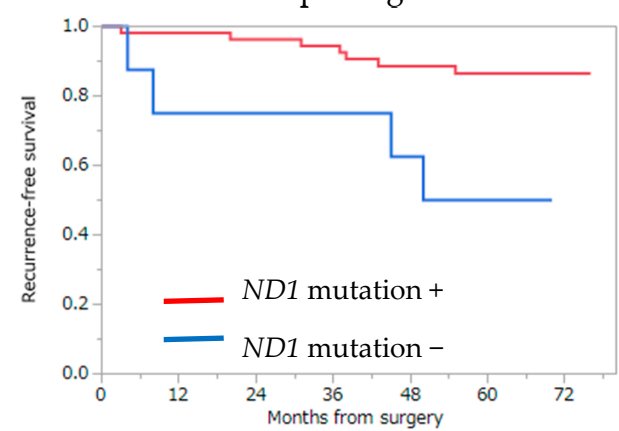

c. Fuhrman grade.

d. ND1 mutation.

Figure 3. Results of Kaplan-Meier analysis for RFS, which showed statistically significant differences by the log-rank test. (a) tumor diameter ( $p=0.0091)$; (b) pT stage $(p=0.0122)$; (c) Fuhrman grade $(p=0.0070)$; and (d) ND1 mutation $(p=0.0006)$ were candidates as postoperative prognostic factors for localized renal cell carcinoma. 
Table 4. Multivariate Cox proportional hazards regression analysis for factors associated with postoperative recurrence of localized RCC.

\begin{tabular}{ccccc}
\hline Variables & Lower 0.95 & Upper 0.95 & Likelihood Ratio of Chi-Square & $p$ Value \\
\hline Tumor diameter & -1.425707 & 0.1053829 & 2.90251154 & 0.0884 \\
Pathological T stage & -1.420865 & 0.2705481 & 1.90465633 & 0.1676 \\
Fuhrman grade & -0.704015 & 1.1331817 & 0.16594524 & 0.6837 \\
Somatic mutation in ND & 0.3042389 & 1.8077773 & 8.11445592 & $0.0044^{* *}$ \\
\hline
\end{tabular}

** Statistical significance was set to $p<0.05$.

Table 5. Univariate analysis of factors predicting CSS after surgery.

\begin{tabular}{|c|c|c|c|}
\hline Variables & No. of Cases & 5-Year CSS Rate (\%) & $p$ Value \\
\hline Age (years) & & & 0.2085 \\
\hline$\leq 60$ & 28 & 100 & \\
\hline$>60$ & 34 & 94.1 & \\
\hline Sex & & & 0.4682 \\
\hline Female & 14 & 100 & \\
\hline Male & 48 & 95.8 & \\
\hline Tumor localization & & & 0.2481 \\
\hline Left & 24 & 100 & \\
\hline Right & 38 & 94.5 & \\
\hline Nephrectomy & & & 0.3356 \\
\hline Total & 42 & 95.2 & \\
\hline Partial & 20 & 100 & \\
\hline Tumor diameter (mm) & & & $0.0415 * *$ \\
\hline$\leq 40$ & 42 & 100 & \\
\hline$>40$ & 20 & 90.0 & \\
\hline Histological type & & & 0.6373 \\
\hline clear & 56 & 96.3 & \\
\hline non-clear & 6 & 100 & \\
\hline pT stage & & & $0.0330 * *$ \\
\hline$\leq \mathrm{pT} 2$ & 57 & 98.2 & \\
\hline$\geq \mathrm{pT} 3$ & 5 & 80.0 & \\
\hline Fuhrman grade & & & 0.1272 \\
\hline $\mathrm{I} / \mathrm{II}$ & 54 & 98.1 & \\
\hline III/IV & 8 & 87.5 & \\
\hline Vessel invasion & & & 0.2890 \\
\hline Presence & 50 & 91.7 & \\
\hline Absence & 12 & 98.0 & \\
\hline ND1 somatic mutation & & & $0.0341^{* *}$ \\
\hline Presence & 19 & 89.5 & \\
\hline Absence & 43 & 100 & \\
\hline
\end{tabular}

Table 6. Multivariate Cox proportional hazards regression analysis for factors associated with CSS after surgery of localized RCC.

\begin{tabular}{ccccc}
\hline Variables & Lower $\mathbf{0 . 9 5}$ & Upper 0.95 & Likelihood Ratio of Chi-Square & $p$ Value \\
\hline Tumor diameter & $-43,798.79$ & $43,776.674$ & 2.20091038 & 0.1379 \\
Pathological T stage & -2.119379 & 1.1119271 & 0.48646922 & 0.4855 \\
Somatic mutation in ND1 & $-24,003.11$ & $24,024.239$ & 3.0118406 & 0.0827 \\
\hline
\end{tabular}


Table 7. Multivariate Cox proportional hazards regression analysis for factors associated with RFS after surgery of localized ccRCC.

\begin{tabular}{ccccc}
\hline Variables & Lower 0.95 & Upper 0.95 & Likelihood Ratio of Chi-Square & $p$ Value \\
\hline Tumor diameter & -1.474545 & 0.0066134 & 3.41616475 & 0.0646 \\
Fuhrman grade & -0.87471 & 0.7815922 & 0.01212236 & 0.9123 \\
Somatic mutation in ND1 & 0.0945703 & 1.5221494 & 5.33970621 & $0.0208^{* *}$ \\
\hline
\end{tabular}

** Statistical significance was set to $p<0.05$.

\section{Discussion}

In this study, we conducted a comparative sequence analysis of mtDNA extracted from FFPE RCC specimens and the paired non-cancerous tissue specimens to determine postoperative genetic markers as potential prognostic factors for the recurrence of RCC. As a result, 30 mutations were found in the ND1 sequence of 19 patients. These mutations were not found in healthy Japanese subjects based on the GenBank database and were confirmed to be somatic by comparing with the paired non-cancerous tissue specimens. Majority of the mutations were heteroplasmic; 16 of 19 cases had one or more heteroplasmic sites. Heteroplasmy suggests the presence of a pathogenic mutation as a cause or result of cancer and was previously shown to have a strong association with mutations [25-27]. In six cases, there were three new mutation sites (C3328Y, C4141Y, and C4197Y) that were not previously reported and were not found in the database. Of these new mutation sites, C3328Y and C4141Y were missense mutations, whereas $\mathrm{L} 8 \mathrm{~F}$ and $\mathrm{R} 279 \mathrm{~W}$ were amino acid changes resulting from the mutations. With respect to amino acid changes, we found mutations that led to changes in amino acids at 12 sites in 10 cases $(52.6 \% ; 10 / 19$ patients). Mutations that lead to amino acid changes may alter protein structures and subsequently affect their function and activity.

We identified an insertion of $\mathrm{C}$ at position 3572 (C3572ins) in patient hk383, which caused a frameshift and an amino acid change. With this insertion, the protein structure of ND1 and complex I function may be significantly altered [28]. This specific mutation in mitochondrial ND1 has been reported in oncocytic thyroid carcinoma [29], oncocytic pituitary adenoma [30], renal oncocytoma, and chromophobe RCC (eosinophilic variant) [28], suggesting that C3572ins mutation in ND1 is associated with oncocytic tumors or variants. Oncocytic is derived from the granular eosinophilic appearance of cytoplasm due to the abnormal accumulation of mitochondria [28]. The patient with the C3572ins mutation (case hk383) also had a granular eosinophilic cytoplasm and was diagnosed with an eosinophilic variant of ccRCC. While a correlation between oncocytosis and tumorigenesis has been suggested [31], the relationship between C3572ins and tumor progression is not clear. In this study, our patient with the C3572ins mutation had metastatic recurrence in the lymph nodes and the adrenal glands eight months after surgery. However, further studies are needed to assess the utility of this mutation as a predictor for disease recurrence.

Our log-rank test revealed that tumor diameter $>40 \mathrm{~mm}$, pT stage $\geq 3$, Fuhrman grade $\geq \mathrm{III}$, and ND1 mutation were associated with worse RFS rates in patients who underwent surgery for localized RCC. Multivariate analysis using these factors revealed that mutations in ND1 were significantly associated with RFS rates. Although larger tumor size, pT stage, and Fuhrman grade were previously reported as poor prognostic factors [32,33], this is the first study to show that mutations in ND1 were predictors of recurrence in localized RCC.

The mechanism of carcinogenesis in RCC has not yet been elucidated; however, genetic factors were shown to be crucial to its development. For example, mutations of the von Hippel-Lindau (VHL) gene on the short arm of chromosome 3 and another locus on the long arm of chromosome 5 were shown to be associated with the carcinogenesis of RCC and are considered as candidate tumor suppressor genes [34,35]. However, factors that determine the speed and progression of RCC or its metastasis are not yet known. In this study, we focused on mitochondria, in particular, since its relationship with oxidative stress and consequent mtDNA mutations might affect the prognosis of 
patients with RCC. Mitochondria has a leading role in critical cellular functions such as glucose and lipid metabolism and apoptosis [36]. Furthermore, mitochondria has endogenous angiogenic factors, such as VEGF and TGF- $\beta 1$, and VHL protein for protein degradation by ubiquitination $[37,38]$. The loss of $V H L$ protein observed in most ccRCC cases suggest that it has contributions to the downregulation of biosynthesis of the oxidative phosphorylation complex. Solid tumors endure a severely hypoxic environment, and adaptation to such a hypoxic environment is a critical step in tumor progression. Increases in markers of oxidative stress, such as ROS and nitric oxide, were found in some patients with RCC [39]. In addition, patients with increased parameters of oxidative stress and decreased antioxidant levels were associated with higher grade, stage and metastatic disease [39].

This is the first study that demonstrates the relationship between mitochondrial ND1 mutations and postoperative recurrence of RCC in a Japanese patient cohort. The Japanese are a single ethnic group and thus tend to show similar responses to treatments such as that observed with interferon therapy for RCC [40] and hepatocellular carcinoma [41]. Additionally, Japanese patients were recently shown to exhibit side effects that were distinct from those observed in Western populations in response to targeted therapy for RCC [42]. Furthermore, mtDNA sequences are stored in databases based on race and continent, and comparison of mtDNA sequences across different ethnic groups and races based on the findings of this study will be useful in determining the prognosis of RCC in Japanese patients in future studies. Finally, our findings showing that over $80 \%$ of the mutations found were heteroplasmic provide very strong evidence that mutations in ND1 can be used as indicators of cancer prognosis in the future [43]. Studies with increased numbers of patients are necessary to confirm and improve the reliability of our findings in the present study.

\section{Materials and Methods}

\subsection{Patients and Tumor Specimens}

In this study, FFPE tissue specimens with accompanying clinical data were collected from a total of 62 patients who consecutively underwent radical surgery for localized RCC (clinical T1-4N0M0) at Tokai University School of Medicine Hospital between January and December 2010 and were retrospectively followed for a minimum of two years. This study was approved by the clinical research review committee of the Tokai University School of Medicine.

\subsection{Assessment of Formalin-Fixed Paraffin-Embedded Tissue Specimens}

Two pathologists microscopically confirmed the location of cancerous tissue and the paired non-cancerous tissue within the FFPE specimens, and tissue punch samples that were obtained with an $18 \mathrm{G}$ needle were in separate $1.5-\mathrm{mL}$ test tubes.

\subsection{Amplification of mtDNA with Polymerase Chain Reaction}

FFPE tissue punch samples were washed three times with $500 \mu \mathrm{L}$ lemosol and three times with 99.5\% ethanol to remove lemosol. Tissues were next incubated with $200 \mu \mathrm{g}$ proteinase K in HMW Buffer (10 mM Tris-Cl pH 8.0, $150 \mathrm{mM} \mathrm{NaCl}, 10 \mathrm{mM}$ EDTA (ethylenediaminetetraacetic acid), $0.1 \%$ SDS (sodium dodecyl sulfate) at $60{ }^{\circ} \mathrm{C}$ for overnight, followed by extraction with phenol-chloroform (Phenol/Chloroform/Isoamyl alcohol, 25:24:1), each twice, at 11,000 rpm at room temperature for $10 \mathrm{~min}$. DNA was precipitated by the addition of $0.1 \mathrm{vol} 3 \mathrm{M} \mathrm{Na}-\mathrm{AcOH}$ and $2.5 \mathrm{vol}$ ice-cold ethanol. After centrifugation at $15,000 \mathrm{rpm}$ at $4{ }^{\circ} \mathrm{C}$ for $20 \mathrm{~min}$, DNA pellets were rinsed with $70 \%$ cold ethanol, dried, and dissolved in TE buffer (10 mM Tris- $\mathrm{HCl}, \mathrm{pH} 8.0$ and $1 \mathrm{mM}$ EDTA). Total mtDNA was amplified by polymerase chain reaction (PCR) with the following primer sets that were designed to cover the entire 957-bp mtDNA ND1 region:

F3274 (5'-ACAGTCAGAGGTTCAATTCCTCTTCT-3'), R3590 (5'-ATAGGAGGCCTAGGTTGAGGTTGACCA-3'), 
F3590 (5'-TGGTCAACCTCAACCTAGGCCTCCTAT-3'),

R3725 (5'-GATGGCTAGGGTGACTTCATATGAGA-3'),

F3731 (5'-ATGAAGTCACCCTAGCCATCATTCTACTA-3'),

R4021 (5'-TCATATGTTGTTCCTAGGAAGATTGTAGT-3'),

ND1-F (5'-TCCGAACTAGTCTCAGGCTTCA-3'),

ND1-R (5'-CACGGAGAATTTTGGATTCTCAG-3').

PCR was performed by Ex Taq ${ }^{\circledR}$ (Takara Bio, Tokyo, Japan) under the following conditions: melting at $95{ }^{\circ} \mathrm{C}$ for $10 \mathrm{~s}$, annealing at $55^{\circ} \mathrm{C}$ for $20 \mathrm{~s}$, and extension at $72{ }^{\circ} \mathrm{C}$ for $30 \mathrm{~s}$, for a total of 35 cycles. PCR products were treated by EXOSAP-IT ${ }^{\circledR}$ (Affimetrix, Santa Clara, CA, USA) and directly sequenced using the Big Dye ${ }^{\circledR}$ Terminator v3.1 Reaction Kit (Applied Biosystems, Torrance, CA, USA) mix and ABI 3500xL DNA sequencer (Life Technologies, Carlsbad, CA, USA). We also confirmed the sequences in the ND1 region three times to confirm the mutations. The ND1 DNA sequence data were assembled using the ATCG software (Genetyx, Tokyo, Japan). Accession numbers for the nucleotide sequences of ND1 obtained from 62 patients included in the present study are LC178840-LC178901.

\subsection{Nucleotide Differentiation Index Analysis}

For $N_{\mathrm{ST}}$ analysis, nucleotide sequences of the ND1 gene of 62 subjects in this study were aligned by ClustalW using the Molecular Evolutionary Genetics Analysis (MEGA, version 6, Tempe, AZ, USA, Pennsylvania, USA, Tokyo, Japan) software $[24,44]$. Common sites in all sequences with gaps were excluded from analysis. mtDNA sequences were compared with the reference mtDNA from 62 healthy long-living Japanese individuals from the Genbank database (Table S1). Mutation sites were used in homology searches across a range of databases (NCBI-dbSNP, MitoMap, Ensemble, JSNP), and NC_012920.1 (GI: 251831106) was chosen as the reference sequence for ND1. Next, 27 segregation sites from ND1 gene sequences were selected. $N_{S T i j}$ for the $i$-site and the $j^{\text {th }}$ subpopulation was defined for the $N_{\mathrm{ST}}$ analysis (Table S2). The $N_{\mathrm{ST}}$ formula was as follows [24]:

$$
N_{S T i j}=\frac{H_{T i}-H_{S i j}}{H_{T i}}
$$

\subsection{Detection of Somatic Mutations in ND1 Gene}

The mtDNA sequences of 62 healthy long-living Japanese individuals were randomly extracted from the Genbank database (Table S1) and were compared with the mtDNA sequences of RCC tissues. Subsequently, mutation sites in the mtDNA sequences of RCC tissues were extracted and determined. By extracting the sequence data of the non-cancerous renal tissue of the same patient, the mutations in the RCC tissue were confirmed to be unique and somatic. In addition, after examining the frequency of these mutations using the MtMap and Genbank databases, they were regarded as mutations in carcinoma tissues.

\subsection{Statistical Analysis}

$\mathrm{JMP}^{\circledR}$ version 12.0.1 (SAS Institute, Cary, NC, USA) was used for all statistical analyses. RFS, CSS, and OS were calculated by the Kaplan-Meier method. Nine clinical and pathological factors were selected to determine their association with RFS and CSS, categorical variables were compared using the chi-square test, and the log-rank test was performed to examine the differences in their effect on RFS and CSS. The nine factors considered were as follows: age ( $\leq 60$ years vs. $>60$ years), sex (male vs. female), nephrectomy (full vs. partial), tumor diameter ( $\leq 40 \mathrm{~mm}$ vs. $>40 \mathrm{~mm}$ ), histology type (ccRCC vs. nccRCC), pT stage ( $\leq$ pT2 vs. $\geq$ pT3), Fuhrman grade (I/II vs. III/IV), microvessel invasion (absence or presence), and ND1 mutations (presence or absence). The median age was used for separating the younger patients from the older ones. As the prognosis of ccRCC, which comprises $70 \%$ of all RCC cases, is unfavorable compared with other RCC types, other histological RCC types 
were included in the nccRCC group for comparison with ccRCC (Table 1). We also analyzed the predictive factors of RFS among the ccRCC subgroup. Multivariate analysis using the Cox proportional hazards model was performed for candidate risk factors, which were statistically significant by the log-rank test. Furthermore, the independence of factors that influenced RFS and CSS was examined. $p$ values less than 0.05 were considered as statistically significant.

\section{Conclusions}

This is the first study to demonstrate a relationship between mutations in ND1 and postoperative recurrence of RCC in Japanese patients. Using microscopic evaluation of FFPE specimens, pathologists confirmed the status of tumors from which DNA was extracted. The $N_{\mathrm{ST}}$ value of 0.005 indicated that RCC was significantly associated with mutations in the mitochondrial ND1 gene. Moreover, we identified 30 mutation sites in 19 patients. Most of the mutations were heteroplasmy, and 16 out of the 19 patients harbored one or more heteroplasmic sites. Additionally, 12 sites had mutations that led to amino acid change mutations and were frequent in 10 out of the 19 patients. Furthermore, the RFS was significantly worse in patients with larger tumors with a diameter of over $>40 \mathrm{~mm}$, those with $\geq \mathrm{pT}$ stage 3, those with Fuhrman grade $\geq$ III, and those with ND1 mutations in RCC specimens. Moreover, multivariate analysis revealed that the presence of ND1 mutations was significantly associated with worse RFS.

Supplementary Materials: Supplementary materials can be found at www.mdpi.com/1422-0067/17/12/2049/s1.

Acknowledgments: This work was partially supported by the Support Center for Medical Research and Education, Tokai University.

Author Contributions: Hakushi Kim, Toshiro Terachi, Naoya Nakamura, and Tomoyoshi Komiyama conceived this study and designed the experiments. Tomoyoshi Komiyama analyzed the sequencing date. Hiroshi Kamiguchi examined the PCR and DNA sequencing. Chie Inomoto and Hiroshi Kajiwara examined the RCC tissue samples and confirmed the pathological diagnosis. Hakushi Kim, Tomoyoshi Komiyama, and Hiroyuki Kobayashi verified the results and wrote the paper. All authors read and approved the final draft of the manuscript.

Conflicts of Interest: The authors declare no conflict of interest.

\section{References}

1. Ferlay, J.; Soerjomataram, I.; Dikshit, R.; Eser, S.; Mathers, C.; Rebelo, M.; Parkin, D.M.; Forman, D.; Bray, F. Cancer incidence and mortality worldwide: Sources, methods and major patterns in GLOBOCAN 2012. Int. J. Cancer 2015, 136, E359-E386. [CrossRef] [PubMed]

2. Lipworth, L.; Tarone, R.E.; McLaughlin, J.K. The epidemiology of renal cell carcinoma. J. Urol. 2006, 176, 2353-2358. [CrossRef] [PubMed]

3. Znaor, A.; Lortet-Tieulent, J.; Laversanne, M.; Jemal, A.; Bray, F. International variations and trends in renal cell carcinoma incidence and mortality. Eur. Urol. 2015, 67, 519-530. [CrossRef] [PubMed]

4. Ljungberg, B.; Bensalah, K.; Canfield, S.; Dabestani, S.; Hofmann, F.; Hora, M.; Kuczyk, M.A.; Lam, T.; Marconi, L.; Merseburger, A.S.; et al. EAU guidelines on renal cell carcinoma: 2014 update. Eur. Urol. 2015, 67, 913-924. [CrossRef] [PubMed]

5. Nguyen, M.M.; Gill, I.S.; Ellison, L.M. The evolving presentation of renal carcinoma in the United States: Trends from the Surveillance, Epidemiology, and End Results program. J. Urol. 2006, 176, 2397-2400. [CrossRef] [PubMed]

6. Jemal, A.; Tiwari, R.C.; Murray, T.; Ghafoor, A.; Samuels, A.; Ward, E.; Feuer, E.J.; Thun, M.J; American Cancer Society. Cancer statistics, 2004. CA Cancer J. Clin. 2004, 54, 8-29. [CrossRef] [PubMed]

7. Siegel, R.; Ma, J.; Zou, Z.; Jemal, A. Cancer statistics, 2014. CA Cancer J. Clin. 2014, 64, 9-29. [CrossRef] [PubMed]

8. Janzen, N.K.; Kim, H.L.; Figlin, R.A.; Belldegrun, A.S. Surveillance after radical or partial nephrectomy for localized renal cell carcinoma and management of recurrent disease. Urol. Clin. N. Am. 2003, 30, 843-852. [CrossRef]

9. Hollingsworth, J.M.; Miller, D.C.; Daignault, S.; Hollenbeck, B.K. Rising incidence of small renal masses: A need to reassess treatment effect. J. Natl. Cancer Inst. 2006, 98, 1331-1334. [CrossRef] [PubMed] 
10. Sorbellini, M.; Kattan, M.W.; Snyder, M.E.; Reuter, V.; Motzer, R.; Goetzl, M.; McKiernan, J.; Russo, P. A postoperative prognostic nomogram predicting recurrence for patients with conventional clear cell renal cell carcinoma. J. Urol. 2005, 173, 48-51. [CrossRef] [PubMed]

11. Frank, I.; Blute, M.L.; Cheville, J.C.; Lohse, C.M.; Weaver, A.L.; Zincke, H. An outcome prediction model for patients with clear cell renal cell carcinoma treated with radical nephrectomy based on tumor stage, size, grade and necrosis: The Ssign score. J. Urol. 2002, 168, 2395-2400. [CrossRef]

12. Antonelli, A.; Cozzoli, A.; Zani, D.; Zanotelli, T.; Nicolai, M.; Cunico, S.C.; Simeone, C. The follow-up management of non-metastatic renal cell carcinoma: Definition of a surveillance protocol. BJU Int. 2007, 99, 296-300. [CrossRef] [PubMed]

13. Eichelberg, C.; Junker, K.; Ljungberg, B.; Moch, H. Diagnostic and prognostic molecular markers for renal cell carcinoma: A critical appraisal of the current state of research and clinical applicability. Eur. Urol. 2009, 55, 851-863. [CrossRef] [PubMed]

14. Pastore, A.L.; Palleschi, G.; Silvestri, L.; Moschese, D.; Ricci, S.; Petrozza, V.; Carbone, A.; di Carlo, A. Serum and urine biomarkers for human renal cell carcinoma. Dis. Markers 2015, 2015. [CrossRef] [PubMed]

15. Schon, E.A.; DiMauro, S.; Hirano, M. Human mitochondrial DNA: Roles of inherited and somatic mutations. Nat. Rev. Genet. 2012, 13, 878-890. [CrossRef] [PubMed]

16. Croteau, D.L.; Bohr, V.A. Repair of oxidative damage to nuclear and mitochondrial DNA in mammalian cells. J. Biol. Chem. 1997, 272, 25409-25412. [CrossRef] [PubMed]

17. Lee, H.C.; Yin, P.H.; Lin, J.C.; Wu, C.C.; Chen, C.Y.; Wu, C.W.; Chi, C.W.; Tam, T.N.; Wei, Y.H. Mitochondrial genome instability and mtDNA depletion in human cancers. Ann. N. Y. Acad. Sci. 2005, 1042, 109-122. [CrossRef] [PubMed]

18. Chatterjee, A.; Mambo, E.; Sidransky, D. Mitochondrial DNA mutations in human cancer. Oncogene 2006, 25, 4663-4674. [CrossRef] [PubMed]

19. Ishikawa, K.; Takenaga, K.; Akimoto, M.; Koshikawa, N.; Yamaguchi, A.; Imanishi, H.; Nakada, K.; Honma, Y.; Hayashi, J. ROS-generating mitochondrial DNA mutations can regulate tumor cell metastasis. Science 2008, 320, 661-664. [CrossRef] [PubMed]

20. Bai, Y.; Guo, Z.; Xu, J.; Zhang, J.; Cui, L.; Zhang, H.; Zhang, S. The 9-bp deletion at position 8272 in region $\mathrm{V}$ of mitochondrial DNA is associated with renal cell carcinoma outcome. Mitochondrial DNA A 2016, 27, 1973-1975. [CrossRef] [PubMed]

21. Grzybowska-Szatkowska, L.; Slaska, B. Mitochondrial NADH dehydrogenase polymorphisms are associated with breast cancer in Poland. J. Appl. Genet. 2014, 55, 173-181. [CrossRef] [PubMed]

22. Gasparre, G.; Iommarini, L.; Porcelli, A.M.; Lang, M.; Ferri, G.G.; Kurelac, I.; Zuntini, R.; Mariani, E.; Pennisi, L.F.; Pasquini, E.; et al. An inherited mitochondrial DNA disruptive mutation shifts to homoplasmy in oncocytic tumor cells. Hum. Mutat. 2009, 30, 391-396. [CrossRef] [PubMed]

23. Yusnita, Y.; Norsiah, M.D.; Rahman, A.J. Mutations in mitochondrial NADH dehydrogenase subunit 1 (mtND1) gene in colorectal carcinoma. Malays. J. Pathol. 2010, 32, 103-110. [PubMed]

24. Komiyama, T.; Iwama, H.; Osada, N.; Nakamura, Y.; Kobayashi, H.; Tateno, Y.; Gojobori, T. Dopamine receptor genes and evolutionary differentiation in the domestication of fighting cocks and long-crowing chickens. PLoS ONE 2014, 9, e101778. [CrossRef] [PubMed]

25. Naviaux, R.K. Mitochondrial DNA disorders. Eur. J. Pediatr. 2000, 159, S219-S226. [CrossRef] [PubMed]

26. He, Y.; Wu, J.; Dressman, D.C.; Iacobuzio-Donahue, C.; Markowitz, S.D.; Velculescu, V.E.; Diaz, L.A., Jr.; Kinzler, K.W.; Vogelstein, B.; Papadopoulos, N. Heteroplasmic mitochondrial DNA mutations in normal and tumour cells. Nature 2010, 464, 610-614. [CrossRef] [PubMed]

27. Wallace, D.C.; Chalkia, D. Mitochondrial DNA genetics and the heteroplasmy conundrum in evolution and disease. Cold Spring Harb. Perspect. Biol. 2013, 5. [CrossRef] [PubMed]

28. Lang, M.; Vocke, C.D.; Merino, M.J.; Schmidt, L.S.; Linehan, W.M. Mitochondrial DNA mutations distinguish bilateral multifocal renal oncocytomas from familial Birt-Hogg-Dube tumors. Mod. Pathol. 2015, 28, 1458-1469. [CrossRef] [PubMed]

29. Gasparre, G.; Porcelli, A.M.; Bonora, E.; Pennisi, L.F.; Toller, M.; Iommarini, L.; Ghelli, A.; Moretti, M.; Betts, C.M.; Martinelli, G.N.; et al. Disruptive mitochondrial DNA mutations in complex I subunits are markers of oncocytic phenotype in thyroid tumors. Proc. Natl. Acad. Sci. USA 2007, 104, 9001-9006. [CrossRef] [PubMed] 
30. Porcelli, A.M.; Ghelli, A.; Ceccarelli, C.; Lang, M.; Cenacchi, G.; Capristo, M.; Pennisi, L.F.; Morra, I.; Ciccarelli, E.; Melcarne, A.; et al. The genetic and metabolic signature of oncocytic transformation implicates HIF1 $\alpha$ destabilization. Hum. Mol. Genet. 2010, 19, 1019-1032. [CrossRef] [PubMed]

31. Yeh, J.J.; Lunetta, K.L.; van Orsouw, N.J.; Moore, F.D., Jr.; Mutter, G.L.; Vijg, J.; Dahia, P.L.; Eng, C. Somatic mitochondrial DNA (mtDNA) mutations in papillary thyroid carcinomas and differential mtDNA sequence variants in cases with thyroid tumours. Oncogene 2000, 19, 2060-2066. [CrossRef] [PubMed]

32. Guinan, P.D.; Vogelzang, N.J.; Fremgen, A.M.; Chmiel, J.S.; Sylvester, J.L.; Sener, S.F.; Imperato, J.P. Renal cell carcinoma: Tumor size, stage and survival. Members of the Cancer Incidence and End Results Committee. J. Urol. 1995, 153, 901-903. [CrossRef]

33. Teng, J.; Gao, Y.; Chen, M.; Wang, K.; Cui, X.; Liu, Y.; Xu, D. Prognostic value of clinical and pathological factors for surgically treated localized clear cell renal cell carcinoma. Chin. Med. J. 2014, 127, 1640-1644. [PubMed]

34. Kovacs, G. Molecular cytogenetics of renal cell tumors. Adv. Cancer Res. 1993, 62, 89-124. [PubMed]

35. Long, J.P.; Anglard, P.; Gnarra, J.R.; Walther, M.M.; Merino, M.J.; Liu, S.; Lerman, M.I.; Zbar, B.; Linehan, W.M. The use of molecular genetic analysis in the diagnosis of renal cell carcinoma. World J. Urol. 1994, 12, 69-73. [CrossRef] [PubMed]

36. Green, D.R.; Reed, J.C. Mitochondria and apoptosis. Science 1998, 281, 1309-1312. [CrossRef] [PubMed]

37. Lisztwan, J.; Imbert, G.; Wirbelauer, C.; Gstaiger, M.; Krek, W. The von Hippel-Lindau tumor suppressor protein is a component of an E3 ubiquitin-protein ligase activity. Genes Dev. 1999, 13, 1822-1833. [CrossRef] [PubMed]

38. Shiao, Y.H.; Resau, J.H.; Nagashima, K.; Anderson, L.M.; Ramakrishna, G. The von Hippel-Lindau tumor suppressor targets to mitochondria. Cancer Res. 2000, 60, 2816-2819. [PubMed]

39. Ganesamoni, R.; Bhattacharyya, S.; Kumar, S.; Chauhan, A.; Mete, U.K.; Agarwal, M.M.; Mavuduru, R.; Kaushik, G.; Mandal, A.K.; Singh, S.K. Status of oxidative stress in patients with renal cell carcinoma. J. Urol. 2012, 187, 1172-1176. [CrossRef] [PubMed]

40. Sazuka, T.; Nihei, N.; Nakamura, K.; Sakamoto, S.; Fukasawa, S.; Komaru, A.; Ueda, T.; Igarashi, T.; Ichikawa, T. Interferon treatment for Japanese patients with favorable-risk metastatic renal cell carcinoma in the era of targeted therapy. Korean J. Urol. 2015, 56, 205-211. [CrossRef] [PubMed]

41. Takada, N.; Takase, S.; Takada, A.; Date, T. Differences in the hepatitis C virus genotypes in different countries. J. Hepatol. 1993, 17, 277-283. [CrossRef]

42. Tomita, Y.; Shinohara, N.; Yuasa, T.; Fujimoto, H.; Niwakawa, M.; Mugiya, S.; Miki, T.; Uemura, H.; Nonomura, N.; Takahashi, M.; et al. Overall survival and updated results from a phase II study of sunitinib in Japanese patients with metastatic renal cell carcinoma. Jpn. J. Clin. Oncol. 2010, 40, 1166-1172. [CrossRef] [PubMed]

43. Park, J.S.; Sharma, L.K.; Li, H.; Xiang, R.; Holstein, D.; Wu, J.; Lechleiter, J.; Naylor, S.L.; Deng, J.J.; Lu, J.; et al. A heteroplasmic, not homoplasmic, mitochondrial DNA mutation promotes tumorigenesis via alteration in reactive oxygen species generation and apoptosis. Hum. Mol. Genet. 2009, 18, 1578-1589. [CrossRef] [PubMed]

44. Tamura, K.; Stecher, G.; Peterson, D.; Filipski, A.; Kumar, S. MEGA6: Molecular Evolutionary Genetics Analysis version 6.0. Mol. Biol. Evol. 2013, 30, 2725-2729. [CrossRef] [PubMed]

(C) 2016 by the authors; licensee MDPI, Basel, Switzerland. This article is an open access article distributed under the terms and conditions of the Creative Commons Attribution (CC-BY) license (http://creativecommons.org/licenses/by/4.0/). 